Dinesh Rathi

School of Library and Information Studies, University of Alberta, Edmonton, AB, Canada

Rynnelle Wiebe

School of Library and Information Studies, University of Alberta, Edmonton, AB, Canada

\title{
Decolonization Efforts by Canadian Public Libraries (Paper)
}

\begin{abstract}
:
The Truth and Reconciliation Commission of Canada's 2015 Calls to Action and the CFLA-FCAB Truth and Reconciliation Committee's 2017 Report and Recommendations provide libraries with information for furthering reconciliation and decolonization efforts. Public libraries in Canada have responded to these documents by undertaking various initiatives, which are communicated by libraries, for example, through websites. This paper analyzed website content of five Canadian public libraries. The findings suggest that libraries have taken various initiatives in different areas including online and physical spaces, collections, and programs. Interestingly, decolonization and reconciliation related work also features in some public libraries' strategic plans.
\end{abstract}

\section{Introduction}

Decolonization is about "dismantling colonialist power in all its forms" (Ashcroft et al, 2001 p.52) including removing invisible facets and structures that exert colonial power (Smith, 2010). Reconciliation involves "establishing and maintaining a mutually respectful relationship between Aboriginal and non-Aboriginal peoples" in Canada (The Truth and Reconciliation Commission of Canada, 2015 p.6). Reconciliation, according to the Commission, is "an ongoing process" and involves, for example, "following through with concrete actions that demonstrate real societal change" (ibid p.16).

The Truth and Reconciliation Commission (TRC) of Canada's (2015) Calls to Action provides critical foundation and direction on reconciliation with Indigenous Peoples of Canada. Drawing upon this work, the CFLA-FCAB's (Canadian Federation of Library Associations - Fédération canadienne des associations de bibliothèques) Truth and Reconciliation Committee's Report and Recommendations (CFLA-FCAB 2017) provide libraries with directions and information for furthering decolonization and reconciliation efforts. The publication of these documents gave momentum to initiatives, which will bring change in Canadian libraries. Public libraries in Canada have responded with various initiatives in areas such as programming, collections and spaces to support reconciliation and decolonization efforts, but not much is reflected on Canadian initiatives in literature. This paper aims to fulfill such gap in the literature. It is important to learn and, through publications, share public libraries' efforts with the community of practitioners and researchers in order to further capitalize on initiatives, and build momentum to bring change in the LIS field, particularly in Canada. Organizations such as public libraries use their websites to communicate information (Wilson 2015) to stakeholders, including patrons. This paper analyzes website-based 
content and presents findings on the decolonization and reconciliation efforts by Canadian public library systems in five cities with large Indigenous populations.

\section{Literature Review}

The Truth and Reconciliation Commission of Canada's (2015) Calls to Action and particularly, the CFLA-FCAB's Report and Recommendations (CFLA-FCAB 2017) are discussed in a limited way in scholarly literature. For example, Smith (2017) discusses the process of developing the CFLA-FCAB Report, and Blair and Wong (2017) reflect on both these reports, discuss libraries' role as a colonial institution and call for libraries to work toward allyship and contribute in decolonization and reconciliation.

Numerous information institutions have responded with decolonization and reconciliation initiatives but there is limited research on such efforts undertaken by various institutions, particularly public libraries post publication of these two reports. For example, Bak, Bradford, Loyer, and Walker (2017), and Griffith (2019) discuss how Canadian archives can respond to the Calls to Action through the development of a guideline. Others focus on responses to the Calls to Action in, for example, Canadian Health Sciences libraries (Giustini 2017; Linton \& Ducas 2017; Maestro \& Chadwick 2017) and academic libraries (Laroque 2018, 3).

Blackburn (2014), in her study of Australian public libraries implementing Indigenous community engagement, stated that " $[\mathrm{t}]$ here is little scholarly literature about initiatives in public library provision for and about Aboriginal and Torres Strait Islander people" (122). Internationally, there has been some research in recent years in documenting decolonization efforts by public institutions like libraries and archives. For example, Reyes-Escudero \& Cox (2017) discuss implementing the ATSILIRN Protocols and Protocols for Native American Archival Material at the University of Arizona Libraries Special Collections to move toward ethical stewardship of their collections. Thorpe and Byrne (2016) and Thorpe and Galassi (2018) discuss Indigenous initiatives in Australian public libraries. The State Library in New South Wales (NSW) adopted the ATSILIRN Protocols as a guide, influencing library governance, management, employment, and other aspects of the library (Thorpe \& Byrne 2016), based on an Indigenous Services business plan (Thorpe \& Galassi 2018). These studies of public library Indigenous initiatives provide insight into how public libraries work towards decolonization and reconciliation, yet there is a gap when it comes to studies of public library initiatives in a Canadian context.

\section{Methodology}

The website content of five public library systems was analyzed to learn about decolonization and reconciliation efforts. The top five cities in Canada having the largest Indigenous populations (Winnipeg (92,810), Edmonton (76,205), Vancouver (61,455), Toronto (46,315), and Calgary $(41,645))$ as reported by the Census data of Statistics Canada (2016) were used as shortlisting criteria for the library systems. The five library systems include Winnipeg Public Library (WPL), Edmonton Public Library (EPL), Vancouver Public Library (VPL), Toronto Public Library (TPL), and Calgary Public Library (CPL). These public library websites were browsed for Indigenousrelated content and services, and were searched with terms such as Indigenous, Aboriginal, decolonization, and reconciliation. This method allows for "content to be combed for themes and patterns" (Luo 2018, 237) and to collect information about the "extent and nature" of library programming (Goulding \& Crump 2017, 31). 


\section{Key Findings}

The public library websites analyzed in this research do not make direct connections to CFLAFCAB's Report and Recommendations (CFLA-FCAB 2017), though there are references to the Calls to Action. Information given on a website related to decolonization efforts can reflect intentional responses to CFLA-FCAB's Recommendations but this is not guaranteed. The thematic content analysis of information available on websites reveals that public libraries have taken a number of initiatives in various areas and some of them are as discussed in the following subsections.

\subsection{Online Spaces}

The CFLA-FCAB (2017) Report calls for decolonization of spaces both digital and physical. WPL, EPL, and CPL websites include sections for Indigenous Services, highlighting Indigenous programs and collections. EPL also features a digital Indigenous space, Voices of Amiskwaciy, a "digital public space to share Indigenous stories [...] owned by the Indigenous community" (EPL, "Voices of Amiskwaciy," n.d., para. 1, 4). The CFLA-FCAB Report suggests that library websites offer the site in Indigenous language translations (CFLA-FCAB 2017, 19, 64), though none of these websites offer this. The CFLA-FCAB's Recommendations for physical spaces to "promote Public Libraries as safe spaces" (CFLA-FCAB 2017, 22, 72) and "[a]dopt a formal statement acknowledging the Treaty, unceded and traditional territory on which the library sits" (41) can also be applied to library websites, and are realized on both CPL and VPL's websites, respectively.

\subsection{Physical Spaces}

Library websites may also describe physical spaces, identifying ways libraries meet CFLA-FCAB Recommendations to have "dedicated space" and "authentic Indigenous designs" (CFLA-FCAB 2017, 40). For example, on its Indigenous Services page, WPL displays images of two spaces designed by an Anishinaabe designer with Indigenous art, which house the Indigenous Resources Collections. Similarly, VPL's Central branch features an Indigenous art installation, and the website explains one branch's Musqueam name, náca?mat ct, and identifies land acknowledgements present at each VPL branch. CPL also has an Indigenous Languages Resource

Centre with Indigenous art installations, part of its Indigenous Placemaking initiative.

\subsection{Programs and Services}

The analysis of website content reveals that libraries provide Indigenous programs and services as recommended in the CFLA-FCAB (2017) Report. Examples of programs include Indigenous film screenings (VPL), craft-making (EPL, WPL), and celebrations (TPL). WPL and EPL also allow users to browse programs online using an "Indigenous" filter. The CFLA-FCAB (2017) Report recommends that libraries offer programs in "multiple languages" (23) that "support Indigenous language revitalization" (34). Both WPL and EPL offer Indigenous language learning programs, and CPL offers short language learning videos online. Libraries are also recommended to "Host elders- or storytellers-in-residence" (CFLA-FCAB 2017, 40). All five library websites include information about this type of programming: WPL's "storytellers and other Knowledge Keepers" (WPL, "Visit our Spaces," 2018, para. 3); EPL's Elder in Residence; TPL's Elders in Residence; CPL's Elders Guidance Circle; and VPL's Indigenous Storyteller in Residence. The CFLA-FCAB (2017) Report also recommends that libraries offer programs to "promote Aboriginal Health practices" $(24,71)$, though none of these websites identify related programs. 


\subsection{Collections}

The CFLA-FCAB's (2017) Recommendations for decolonizing collections include offering "appropriate and relevant materials" (12), "multi-language collections" (70), materials reflecting Aboriginal Health practices $(24,71)$, and residential school records or website links to residential school online registries (27). The report further states that libraries must "actively seek out the work of Indigenous creators for inclusion in their collections and in addition, institute a robust deselection system that recognizes cultural appropriation and historical inaccuracy" (35). All five library websites identify Indigenous collections that include items in one or more Indigenous languages (e.g., Cree and Inuktitut in EPL). Further, libraries present featured Indigenous book lists categorized by language (e.g., EPL) or age (e.g., TPL) on their websites. Other libraries like WPL and VPL offer additional Indigenous resources through online LibGuides. WPL's Indigenous Info Guides include topics such as treaties, residential schools, sixties scoop, and Manitoba organizations. VPL's Indigenous Resource Guides include community resources and topics relating to Indigenous ancestry, women, and residential schools.

\subsection{Strategic Plans}

The CFLA-FCAB Report as a whole provides guidance on library planning and implementing recommendations, and advises that libraries "[a]cknowledge that First Nations, Métis, Inuit are key stakeholders and involve them in developing new facilities, developing library related strategies, programming, and policies" (CFLA-FCAB 2017, 24, 70). The five library websites include information about the library system and its strategic plans, and WPL, EPL, VPL, and CPL have strategic goals or activities related to working with Indigenous communities. In fact, both EPL and VPL reference the Calls to Action while discussing these goals. Libraries like TPL and CPL discuss the involvement of Indigenous community members through TPL's Indigenous Advisory Committee and CPL's Indigenous Services team. Though there is evidence that Indigenous community members are involved in library functions through committee work, interestingly, none of the strategic planning documents shared on the websites explicitly state how libraries are involving Indigenous community members in overall strategic planning.

\section{Conclusion}

This paper presents findings by analyzing website content to understand and learn about the decolonization and reconciliation efforts by five public library systems operating in Canadian cities having significant Indigenous populations. Public libraries have taken a number of initiatives in various areas such as online and physical spaces, collections and programs. This paper aims to fulfill a significant gap in the literature on public libraries' decolonization and reconciliation efforts by reviewing them in the context of the CFLA-FCAB (2017) Report and Recommendations. The limitations of this study are that findings are based on website content, making it difficult to assess whether these initiatives are because of the Calls to Action or CFLA-FCAB Report as it is not explicitly stated on the websites (Maestro \& Chadwick 2017), and limiting them to information available on websites at the time of data collection. This paper connects to the Congress 2020 theme of confronting colonialism. 


\section{Reference List:}

Ashcroft, B., Griffiths, G., \& Tiffin, H. (2001). Key concepts in post-colonial studies. London, UK: Routledge.

Bak, G., Bradford, T., Loyer, J., \& Walker, E. (2017). Four views on archival decolonization inspired by the TRC's Calls to Action. Fonds d'Archives, 1, 1-20.

Blackburn, F. (2014). An example of community engagement: Libraries ACT and the ACT Aboriginal and Torres Strait Islander Communities. Australian Academic \& Research Libraries, 45(2), 121-138.

Blair, J., \& Wong, D. (2017). Moving in the circle: Indigenous solidarity for Canadian libraries. Partnership: The Canadian Journal of Library and Information Practice and Research, 12(2), 1-7.

Calgary Public Library. (2019). Potentials realized: Calgary Public Library strategic plan 20192022. Retrieved from https://calgarylibrary.ca/assets/PDFs/2019/20192022_Strategic_Plan_2019_Initiatives.pdf

Calgary Public Library. (n.d.). Indigenous placemaking. Retrieved from https://calgarylibrary.ca/connect/indigenous-services/indigenous-placemaking/

CFLA-FCAB. (2017). Truth and reconciliation committee report and recommendations. Retrieved from http://cfla-fcab.ca/en/indigenous/trc_report/

Edmonton Public Library. (2019). Strategic goals 2019-2023: Business plan 2019-221. Retrieved from https://d4804za1f1gw.cloudfront.net/wpcontent/uploads/sites/18/2015/06/01150026/EPLBusinessPlan2018_Booklet_FINAL_low res_AUG2018_v5.pdf

Edmonton Public Library. (n.d.). Voices of Amiskwaciy. Retrieved from https://www.epl.ca/digital-storytelling/\#voa

Giustini, D. (2017). As Canadian health librarians we must now move ahead on the Truth and Reconciliation (TRC) Calls to Action. Journal of the Canadian Health Libraries Association (JCHLA), 38(3), 118-120.

Goulding, A., \& Crump, A. (2017). Developing inquiring minds: Public library programming for babies in Aotearoa New Zealand. Public Library Quarterly, 36(1), 26-42.

Griffith, J. (2019). Settler colonial archives: Some Canadian contexts. Settler Colonial Studies, 9(3), 320-340.

Laroque, S. (2018). Making meaningful connections and relationships in cataloguing practices: The Decolonizing Description Project at University of Alberta Libraries. Evidence Based Library and Information Practice, 13(4), 2-6.

Linton, J., \& Ducas, A. (2017). A new tool for collection assessment: One library's response to the calls to action issued by Canada's truth and reconciliation commission. Collection Management, 42(3-4), 256-279.

Luo, L. (2018). Health information programming in public libraries: a content analysis. Public Library Quarterly, 37(3), 233-247.

Maestro, L., \& Chadwick, D. (2017). Canadian health libraries' responses to the Truth and Reconciliation Commission's Calls to Action: A literature review and content analysis. Journal of the Canadian Health Libraries Association (JCHLA), 38(3), 92-101. 
Reyes-Escudero, V., \& Cox, J. W. (2017). Survey, understanding, and ethical stewardship of Indigenous collections: A case study. Collection Management, 42(3/4), 130-138.

Smith, A. (2010). Decolonization in unexpected places: Native evangelicalism and the rearticulation of mission. American Quarterly, 62(3), 569-590.

Smith, S. (2017). The creation of the CFLA/FCAB truth and reconciliation committee: The first report. Partnership: The Canadian Journal of Library and Information Practice and Research, 12(1), 1-4.

Statistics Canada. (2016). Aboriginal Peoples highlight tables, 2016 census. [Catalogue number 98-402-X2016009]. Retrieved from https://www12.statcan.gc.ca/censusrecensement/2016/dp-pd/hlt-fst/abo-aut/Table.cfm?Lang=Eng\&T=102\&S=88\&O=A

Thorpe, K., \& Byrne, A. (2016). Indigenous voices in the State Library of New South Wales. Australian Library Journal, 65(1), 17-29.

Thorpe, K., \& Galassi, M. (2018). Diversity, inclusion \& respect: Embedding Indigenous priorities in public library services. Public Library Quarterly, 37(2), 180-194.

Toronto Public Library. (2016). Toronto Public Library strategic plan 2016-2019. Retrieved from https://www.torontopubliclibrary.ca/content/about-the-library/strategic-plan/pdfs/stratplan-2016-2019.pdf

Vancouver Public Library. (2017). VPL 2020 strategic plan 2017-2020. Retrieved from https://www.vpl.ca/sites/vpl/public/VPL2020-Booklet_sml.pdf

Wilson, D.E. (2015), "Web content and design trends of Alabama academic libraries", The Electronic Library, 33(1), 88-102.

Winnipeg Public Library. (2015). Winnipeg Public Library strategic plan 2015-2020. Retrieved from http://inspiringideas.wpl.winnipeg.ca/wp-content/uploads/WPL_StrategicPlan1520E.pdf

Winnipeg Public Library. (2018, Dec 17). Visit our spaces. Retrieved from https://wpl.winnipeg.ca/library/ourservices/IndigenousServices.asp

Truth and Reconciliation Commission of Canada. (2015). Honouring the Truth, Reconciling for the Future: Summary of the Final Report of the Truth and Reconciliation Commission of Canada. Retrieved from http://nctr.ca/assets/reports/Final\%20Reports/Executive_Summary_English_Web.pdf 